\title{
GRAMMATICAL PARALLELS IN BANTU
}

A parallel thought-form to the classical internal accusative occurs in Kiswahili.

A well-known idiom in the Bantu language is known as the 'passive of the prepositional form'. The grammatical interest of this construction is centred in what appears to be a retained accusative of the classical type. A typical example would be-'Umeletewa kikombe na Abdalla'literally 'you have been brought [2nd pers. sing. perf. indicative pass. (prepositional form) of 'kuleta'-to bring] a cup-by Abdalla'.- Now the normal construction would be 'kikombe kimeletwa na Abdalla''a cup (subject) has been brought by Abdalla'-whereas the more idiomatic passive construction makes 'you' the subject and retains he real subject 'cup' in the accusative case-if one may presume to speak of 'cases' in a Bantu tongue.

The same idiom is found in Kikuyu, another well-known Bantu language, where the sentence would read 'niwarehero gikombe ni Abdalla'; and in Kihēhē-'Amere kikombe na Abdalla'.

King's African Rifles,

J. R. THORNHILL POLLARD.

East Africa Force.

\section{RE V I E W S}

Cisalpine Gaul: Social and Economic History from 49 B.c. to the Death of Trajan. By G. E. F. Chilver. Oxford: Clarendon Press, 194I. Pp. viii+ 235, 2 maps. 17 s. $6 d$.

Dr. Chilver's scholarly and detailed study of Cisalpine Gaul covers the period of its greatest prosperity. Not united politically with Italy till 42 B.C. and containing a large 'native' population in the foot-hills of the Alps, it lagged some fifty years behind the rest of the peninsula in its development, but in the first half of the first century A.D. its inhabitants, profiting by its natural resources and its position on the main lines of communication between Italy and the rest of Europe, acquired the wealth which qualified them to hold the highest positions at Rome during the next two generations. After the death of Trajan there becomes evident a decline in the vigour of municipal life, due in part to the preoccupation of the best and richest families with the imperial service.

Inscriptions are skilfully used to supplement the scanty literary evidence for the conditions of life in Cisalpine Gaul during this period. The distribution and composition of the population, the part played by the upper classes in municipal and imperial affairs, the recruiting of legions in this part of Italy, the agriculture and industries of the region, are among the subjects discussed. The author is inclined to attribute the agricultural crisis of 'Trajan's reign to over-production, especially of wine. In a chapter on religion, stress is laid on the survival of native cults and there is a full, if somewhat inconclusive, discussion of the distinction between VIviri and Augustales. Writing on 'Virgil and Cisalpine Culture', the author suggests that Virgil's Cisalpine birth made 